\title{
Evaluation of Some Phytochemicals in Raw and Cooked Ipomea batatas (Lam), (Sweet Potato), Solanum tuberosum (Irish Potato) and Dioscorea cayenensis (Yellow Yam)
}

\author{
*AKPE, MA; ASHISHIE, PB; AKONJOR, OA \\ Department of Pure and Applied Chemistry, University Of Calabar, Calabar, Nigeria \\ *Corresponding Author Email: akomayeakpe2015@gmail.com
}

\begin{abstract}
Cooking induces numerous phytochemical changes in food. This study is aimed at determining the amount of phytochemicals present in raw and cooked sweet potato, Irish potato and yellow yam. The amount of tannin, alkaloids, saponin, flavonoids and phenol were determined in raw and cooked samples of each food crop. The result showed that tannin, alkaloids, saponin, flavonoids, phenol contents was high in Irish potato and sweet potato but was far much present in Irish potato, while it was seen in minute quantity in yellow yam. The values obtained for each phytochemicals in each food sample raw and cooked respectively, in $\mathrm{mg} / 100 \mathrm{~g}$ were; Yellow yam: Tannins $(0.10$ and Nil), Alkaloids (2.00 and 0.51), Flavonoids (1.18 and 0.87), Saponins (2.00 and 1.02) and Phenols (0.72 and 0.10). Sweet potato: Tannins (0.32 and 0.28), Alkaloids (2.17 and 0.62), Saponins (2.10 and1.58), Flavonoids (1.28 and 0.97) and Phenols (1.42 and 0.72). Irish potato: Tannins (0.55 and 0.49), Alkaloids (2.17 and 0.81), Saponins (4.00 and 2.13), Flavonoids (5.00 and 2.91) and Phenols (2.00 and 0.91). The \% loss of phytochemicals after cooking were; Yellow yam: Tannins (Nil), Alkaloids (74.5), Saponins (49.0), Flavonoids (26.3) and Phenols (86.1). Sweet potato: Tannins (12.5), Alkaloids (71.4), Saponins (24.8), Flavonoids (24.2) and Phenols (49.3). Irish potato: Tannins (10.0), Alkaloids (62.7), Saponins (46.8), Flavonoids (41.8) and Phenols (54.5). These results indicate that boiling of the samples seems to reduce their phytochemical contents as the raw samples showed higher amounts of the phytochemicals. The results also revealed that Tannins are more stable to heat across the 3 food samples, followed by Flavonoids, Saponins, Phenols and Alkaloids. The loss in some of the phytochemicals after cooking did not significantly affect the nutritional quality of the food samples.
\end{abstract}

DOI:https://dx.doi.org/10.4314/jasem.v25i9.3

Copyright: Copyright $(2) 21$ Akpe et al. This is an open access article distributed under the Creative Commons Attribution License (CCL), which permits unrestricted use, distribution, and reproduction in any medium, provided the original work is properly cited.

Dates: Received: 09 May 2021; Revised: 12 August 2021; Accepted: 12September 2021

Keywords: Evaluation, Phytochemicals, Yellow yam, Potato, Cooked

Root and tuber crops plays a major role in the food security of many developing countries and through the development and promotion of better management of these crops, the livelihoods of the poor people who depend on them will be improved. Root crops were regarded as food mainly for the poor, and have played a very minor role in international trade (FAO, 1990). This misconception has lingered for so long because of the lack of appreciation of the number of people who depend on these root crops and the number of lives that have been saved during famine or disasters by root crops. Root crops contain an appreciable amount of carbohydrate, vitamins and minerals and may have a competitive production advantage in terms of energy yield per hectare over areas produced in ecologically difficult condition (UNIFEM, 2002). The nutritional value is the main concern when a crop is being considered as a food source. Due to the emphasis placed on the nutritional value of food by consumers, a great need exist for information on the nutritional contents of root crops as they are considered an excellent energy source. Tubers are very rich in carbohydrates, ranging between $73-80 \%$ which is mainly starch. Phytochemicals are organic compounds manufactured by plants through primary or secondary metabolism. These compounds include saponins, tannins, alkaloids, flavonoids, phenols, oxalates, phytates, carotenes, etc. Tannins (also called tannic acid) belong in the group of polyphenolic compounds. Tannins are water soluble astringent, bitter polyphenolic compounds of high molecular weight found occurring naturally in the vacuoles or surface wax of quite a number of parts of many edible and non-edible plants (Reed, 1995). Also, tannins are found in plant based products such as chocolate, wines, nuts-almonds, acorns, hazelnuts, walnuts, arela nut, fruit juices, ciders beer, cheeses, some fermented foods, ice creams, beverages, smoked foods, herbs and herbal preparation etc (Navia, 2002; Wolke and Parrish, 2005; Vattem et al., 2005). The presence of tannins in plants and plant products is specifically for the purpose of defense against predation and growth regulation (Salunkhe et al., 1990). Alkaloids are a huge group of naturally occurring organic compounds which contains nitrogen atom or atoms (amino or amido group in some cases) in their structures. These

*Corresponding Author Email: akomayeakpe2015@gmail.com 
are nitrogen atoms causes alkalinity of the compounds. These nitrogen atoms are usually situated in some rings (cyclic) system. For example indole alkaloids are those that contain nitrogen atom in the indole ring system. Some groups of structurally related alkaloids are present in plants from few to even 30. These alkaloids belong to the same class but have some differences in their structure and one of them usually occur in majority (Joanna et al, 2019). Ezeocha et al., (2012) studied the impact of cooking on the proximate composition and anti nutritional factors of water yam using proximate content such as ash, crude protein (10.27) carbohydrate, crude fibre, crude lipid and tannin significantly reduced in the boiled tuber. Chinedu et al., (2017) studied the evaluation of antinutrients and mineral composition of trifoliate yam using standard method. The results of the antinutrients of determination of trifoliate yam showed that the phytate and cyanide contents (9.858 and $87.26 \mathrm{mg} / 100 \mathrm{~g}$ respectively) of the four powder were higher than that of the flour paste (5.8 and $74.76 \mathrm{mg} / 100 \mathrm{~g}$ respectively). While oxalate, tannin and trypsin inhibitor contents were (18.16, 7.4 and $0.16 \mathrm{mg} / 100 \mathrm{~g}$ ). Abdul-rasaq et al., (2018) studied the antinutritional and vitamin composition of high quality yam flour as affected by yam species, treatment and drying method. The results showed that four different yam tubers which were pretreated with $0.28 \%$ potassium metabisulphate for 15 minutes and blanching at $70^{\circ} \mathrm{Cfor} 15 \mathrm{~min}$. indicates that the antinutritional factors in the high quality yam flour were significantly $(\mathrm{p}<0.5)$ affected by yam species, pretreatment and drying methods. The study further states that the low level of alkaloids $(0.02 \mathrm{mg} / 100 \mathrm{~g})$ and phytates $(13.43 \mathrm{mg} / 100 \mathrm{~g})$ in the flour sample underscores it safety for absorption in the body when consumed or used as food formulation. According to Lewu et al., (2010), the comparative assessment of the nutritional value of commercially available cocoyam and potato in South Africa was carried out and the study concluded in saying that cooking the both tubers remarkably reduced the anti-nutrient contents of both tubers. Several researches have been carried out on the phytochemical quality of sweet potato, Irish potato and yellow yam and other tubers or starchy food crops in Africa and the world at large. However, the effect of boiling and heating (increased temperature) on the quantity of phytochemicals in food has not been fully studied to ascertain the effect of cooking or boiling these food tubers on their phytochemical quality. This study is aimed at evaluating the effect of heating or cooking on the amount of phytochemicals in these foods and informs or educates the public.

\section{MATERIALS AND METHODS}

Sample collection and pretreatment: Sweet potato, Irish potato and yellow yam samples were bought from the popular Marian market in Calabar, Cross River State, Nigeria. The tubers collected contained large, middle and small tuber sizes that were not damage during harvest and which were not attack by pests. The tubers were packaged in a polyethylene bag and transported to the laboratory for further treatment and analysis.

Sample preparations: The sample was prepared for sweet potato, Irish potato and yellow yam which were washed and peeled carefully using a stainless steel knife and the peeled samples were washed, rinsed with deionized water and then sliced. Some slices were preserved for further analysis while some of the slices of the tubers were boiled for further analysis.

Chemicals or reagents used: The following are the chemicals used for this research work. Wade reagent $\left(0.03 \%\right.$ solution of $\left.\mathrm{FeCl}_{3} \cdot 6 \mathrm{H}_{2} 0\right)$, distilled water, methyl red indicator, concentrated $\mathrm{NH}_{4} \mathrm{OH}$ solution, aliquots, standardized $\mathrm{KMnO}_{4}$ solution, $\mathrm{HCl}$, methanol, $\mathrm{H}_{2} \mathrm{SO}_{4}$ and Vinillin-HCl.

Qualitative Analysis of Tannin:5g of the crushed sample was measured using a weighing balance and transferred into three different beakers then $50 \mathrm{mls}$ of water was added to each sample and it was allowed to stand for about 50 minutes to 1 hour to allow it settled. After settling, $0.5 \mathrm{ml}$ of $5 \%$ Ferric chloride was added and the development of a dark-bluish black colour indicated the presence of tannins. The same process was also carried out for cooked samples.

Quantitative Analysis of Tannin: $0.5 \mathrm{~g}$ of the samples was weighed into plastic bottle and $50 \mathrm{~cm}^{3}$ of water was added and shaken and stirred for 1 hour in a shaker. It was then filtered and $5 \mathrm{~cm}^{3}$ of the extract was measured to a test tube and mixed with $3 \mathrm{~cm}^{3}$ of $0.1 \mathrm{~N}$ $\mathrm{HCl}, 3$ drops of ferrocyanide was added. It was allowed to stand for 10minutes, and then measured in the UV-Spectrophotometer of $605 \mathrm{~nm}$. Blank too was determined.

Calculation:

$$
\text { Tannins }\left(\frac{\mathrm{mg}}{100 \mathrm{~g}}\right)=\left[\frac{\text { Absorbance of sample }- \text { Absorbance of blank }- \text { intercept }}{\text { slope } \mathrm{x} \text { density } \mathrm{x} \text { weight of sample }}\right.
$$


Qualitative test for Saponins using sodium bicarbonate solution (honey comb test): $0.5 \mathrm{mg}$ of extract was taken in a test tube and few drops of 5\% sodium bicarbonate solution was added the mixture was shaken vigorously and kept for 3 minutes, the formation of honey comb like troth was observed which shows the presence of saponins in the samples for both raw and cooked.

Quantitative analysis for saponins: Separatory funnel, shaker and stirrer, 20\% ethanol, diethylether, nbutanol, 5\% sodium chloride and distilled water and apparatus listed above for alkaloids were used.5.0 $\mathrm{g}$ of samples was dispersed in $50 \mathrm{~cm}^{3}$ of $20 \%$ ethanol in a beaker. The suspension was heated over a hot water bath for four hours with a continuous stirring at about $60^{\circ} \mathrm{C}$. The mixture was filtered after 4 hours and the residue was re-extracted with another $25 \mathrm{~cm}^{3}$ of $20 \%$ ethanol. The combine extract was concentrated and reduce to $40 \mathrm{~cm}^{3}$ over water bath at $90^{\circ} \mathrm{C}$. The sample was transferred into a separatory funnel and $20 \mathrm{~cm}^{3}$ of diethyl ether was added and shaken thoroughly. Aqueous layer of the extracts was recovered while the either layer was discarded. The purification process was repeated for all samples and $60 \mathrm{~cm}^{3}$ of n-butanol was added and the extract was washed twice with $10 \mathrm{~cm}^{3}$ of $5 \%$ aqueous sodium chloride. The remaining extracts was evaporated in a water bath and dried in an oven to a constant weight, the saponin content was then calculated in percentage.

$$
\text { Saponin contents }=\left[\frac{\text { Weight in Quantity }}{\text { Sample weight }} \times \frac{100}{1}\right.
$$

Qualitative test for flavonoids in the samples using lead acetate solution:10mg of extract was taken and few drops of $10 \%$ lead acetate solution was added which was carefully observed, formation of yellow colour precipitate was observed which indicate the presence of flavonoids.

Quantitative analysis of flavonoids using lead acetate: Weighing balance (analytical grade), beakers, measuring cylinder, water bath, spatula, funnel, wash bottle, filter paper, oven, desiccator and 50\% methanol were used.5g of each sample was weighed into different beakers and extracted with $50 \mathrm{~cm}^{3}$ of $80 \%$ methanol at room temperature for 1 hour. The solution was filtered using filter paper. The filtrate was evaporated to dryness over water bath and oven.

Qualitative test for phenol using ferric chloride solution: $0.2 \mathrm{~g}$ of the extract was weight and treated with $5 \%$ ferric chloride and observes for the formation of deep blue colour which indicates the presence of phenol in both raw and cooked samples of yellow yam, sweet potato and Irish potato.

Quantitative test for phenol: Total polyphenol content was estimated using folin-crocaltev (FC) assay which is widely used in routine analysis (Wright et al, 2000; Atoui et al, 2005) a known amount of sample extract $(10 \mathrm{mg} / \mathrm{ml})$ was mixed with $1.0 \mathrm{ml}$ of $\mathrm{FC}$ reagent and $0.8 \mathrm{ml}$ of $2 \% \mathrm{Na}_{2} \mathrm{Co}_{3}$ was added and the volume was made up to $10 \mathrm{ml}$ using water-methanol (4:6) as diluting fluid. Absorbance was read at $740 \mathrm{~nm}$ after 30min using UV spectrophotometer. Tannin acid (0$800 \mathrm{mg} / \mathrm{l}$ ) was using to produce standard calibration curve. The total phenolic content was expressed in $\mathrm{mg}$ of tannic acid equivalent (tae)/100 $\mathrm{g}$ of samples.
Qualitative test for Alkaloids using Wagner's reagent: $10 \mathrm{mg}$ of extract was taken and few drops of Wagner's reagent were added and the formation of a reddish brown precipitate was observed which indicated the presence of Alkaloids.

Quantitative analysis of Alkaloids: Materials used were weighing balance (analytical grade), beakers, measuring cylinder, water bath, spatula, funnel, wash bottle, oven and desiccator, filter paper, acetic acid, and ethanol, dilute ammonium hydroxide, concentrated ammonia and distilled water.5g of sample was weighed into a beaker; $100 \mathrm{~cm}^{3}$ of $100 \%$ acetic acid in ethanol (1:1 ratio) was measure into the sample container and covered to stand for 4 hours. The extracted sample was filtered after four hours. It was then concentrated using water bath to a quantity of the original volume. Ammonia solution was added to the concentrated samples (extract) in a drop-wise manner until the precipitate was allowed to settle, then was filtered and washed with dilute ammonium hydroxide. The residue left was taken as the crude alkaloid and was dried in an oven and weighed.

\section{Results and Discussion}

The results of qualitative analysis are presented in Table 1, those of quantitative analysis are shown in Table 2, while the percentage loss of phytochemicals after cooking are presented in Table 3. From the results above, it shows that the mean phytochemicals contents are higher in raw samples than in the cooked samples. Flavonoids showed significantly high amount of both raw and cooked samples of yellow yam, sweet potato and Irish potato, in both qualitative and quantitative tests. Saponins were greatly present in both raw and cooked samples of yellow yam, sweet potato and Irish potato. The presence of alkaloids in both raw and 
cooked samples was seen in greater amount. Tannins: Tannin was very little in raw sample of yellow yam but was absent in cooked sample of yellow yam. However, it was presence in other samples of sweet potato and Irish potato. Phenols were present in all the samples The results also indicated that raw samples of sweet potato and Irish potato are far more higher and greater in phytochemicals than that of cooked samples
The raw results shows that flavonoids for Irish potato $(5.00)>$ sweet potato (1.28) > yellow yam (1.18). For saponins, Irish potato $(4.00)>$ sweet potato $(2.10)>$ yellow yam (2.00). For Alkaloids, Irish potato (2.17) and sweet potato $(2.17)>$ yellow yam (2.00). For phenols, Irish potato $(2.00)>$ sweet potato $(1.42)>$ yellow yam (0.72). For tannins, Irish potato $(0.55)>$ sweet potato $(0.32)>$ yellow yam (not visible)

Table 1:Results of qualitative analysis of phytochemical in aqueous extract of the samples

\begin{tabular}{|c|c|c|c|c|c|c|c|c|}
\hline \multirow{2}{*}{$\begin{array}{l}\mathrm{S} / \\
\mathrm{n} .\end{array}$} & \multirow{2}{*}{$\begin{array}{l}\text { Phytochem } \\
\text {.Comps. }\end{array}$} & \multirow[t]{2}{*}{ Test reagent } & \multicolumn{2}{|c|}{ Yellow yam } & \multicolumn{2}{|c|}{ Sweet potato } & \multicolumn{2}{|c|}{ Irish potato } \\
\hline & & & Raw & cooked & Raw & Cooked & Raw & cooked \\
\hline 1. & Tannins & Ferric chloride $\left(\mathrm{FeCl}_{3}\right)$ & + & - & + & + & + & + \\
\hline 2. & Alkaloids & Wagner's Reagent & ++ & + & ++ & + & ++ & + \\
\hline 3. & Saponin & Sodium Bicarbonate $\left(\mathrm{NaHCO}_{3}\right)$ & ++ & + & ++ & + & ++ & + \\
\hline 4. & Flavoniods & Lead acetate $\left(\mathrm{Pb}\left(\mathrm{C}_{2} \mathrm{H}_{3} \mathrm{O}_{2}\right)_{2}\right.$ & + & + & ++ & + & +++ & ++ \\
\hline 5. & Phenol & Ferric chloride $\left(\mathrm{FeCl}_{3}\right)$ & + & + & ++ & + & ++ & + \\
\hline
\end{tabular}

Table 2: Phytochemical content of Raw and Cooked Samples in $\mathrm{mg} / 100 \mathrm{~g}$

\begin{tabular}{llllllll}
\multicolumn{9}{c}{ Table 2: Phytochemical content of Raw and Cooked Samples in mg/100g } \\
\hline S/N & $\begin{array}{l}\text { Phytochem. } \\
\text { Compounds }\end{array}$ & Yellow yam & \multicolumn{3}{c}{ Sweet potato } & Irish potato \\
& & Raw & Cooked & Raw & Cooked & Raw & cooked \\
1. & Tannins & $0.10 \pm 0.01$ & - & $0.32 \pm 0.01$ & $0.28 \pm 0.01$ & $0.55 \pm 0.01$ & $0.49 \pm 0.01$ \\
2. & Alkaloids & $2.00 \pm 0.02$ & $0.51 \pm 0.01$ & $2.17 \pm 0.02$ & $0.62 \pm 0.01$ & $2.17 \pm 0.02$ & $0.81 \pm 0.01$ \\
3. & Saponin & $2.00 \pm 0.01$ & $1.02 \pm 0.01$ & $2.10 \pm 0.02$ & $1.58 \pm 0.01$ & $4.00 \pm 0.10$ & $2.13 \pm 0.02$ \\
4. & Flavoniods & $1.18 \pm 0.01$ & $0.87 \pm 0.01$ & $1.28 \pm 0,01$ & $0.97 \pm 0.01$ & $5.00 \pm 0.10$ & $2.91 \pm 0.02$ \\
5. & Phenols & $0.72 \pm 0.01$ & $0.10 \pm 0.01$ & $1.42 \pm 0.01$ & $0.72 \pm 0.01$ & $2.00 \pm 0.02$ & $0.91 \pm 0.01$ \\
\hline
\end{tabular}

Table 3: Percentage (\%) loss of Phytochemicals after cooking

\begin{tabular}{lllll}
\hline S/n. & Phytochem. & $\begin{array}{l}\text { Yellow } \\
\text { yam }\end{array}$ & $\begin{array}{l}\text { Sweet } \\
\text { potato }\end{array}$ & $\begin{array}{l}\text { Irish } \\
\text { potato }\end{array}$ \\
\hline 1. & Tannins & - & 12.5 & 10.9 \\
2. & Alkaloids & 74.5 & 71.4 & 62.7 \\
3. & Saponin & 49.0 & 24.8 & 46.8 \\
4. & Flavoniods & 26.3 & 24.2 & 41.8 \\
5. & Phenol & 86.1 & 49.3 & 54.5 \\
\hline
\end{tabular}

For the cooked samples: saponin in Irish potato (2.13) $>$ sweet potato (1.58) > yellow yam (1.02), for flavonoid, Irish potato $(2.91)>$ sweet potato $(0.97)>$ yellow yam (0.87). For phenols, Irish potato $(0.91)>$ sweet potato and yellow yam (0.72) respectively. For alkaloids, Irish potato $(0.81)>$ sweet potato $(0.62)>$ yellow yam (0.51). For tannins, Irish potato $(0.49)>$ sweet potato $(0.28)>$ yellow yam $>(0.10)$. From the result above, raw samples of yellow yam, sweet potato and Irish potato shows significantly higher amount of the phytochemicals except tannin while raw samples tend to show little amount of the phytochemicals. The result shows that flavonoids are higher in raw samples of yellow yam, sweet potato and Irish potato. This is followed by saponins, alkaloids, phenol then tannins which is present in small amount in raw form of yellow yam. This is evident that raw samples of sweet potato and Irish potato has greater amount of the phytochemicals while for tannins, it is not seen. However, when the samples are boiled or cooked, the phytochemicals contents of alkaloids, tannins, flavonoids, phenol and saponins tend to reduce as a result of boiling of the samples. This agrees with the study of Ezeocha et al.(2012) on water yam and the study by Lewu et al. (2010) cocoyam and other tubers in South Africa and concluded that cooking remarkably reduced the anti-nutrient contents of tubers. From the results, flavonoids are much present in Irish potato same with saponins, phenols, alkaloids, flavonoids and tannins which is followed by sweet potato before yellow yam which shows that dietary protein in humans plays a protective role against hypertension, stroke, cardiac dysfunctions, renal damage, hypercalciuria, kidney, stones and osteoporosis (Demigne et al., 2004).

Conclusion: Yellow yam, sweet potato and Irish potato contains an appreciable amount of phytochemicals viz; alkaloids, saponins, tannins, flavonoids and phenolic compounds indicating that 
they are good enough for consumption having known the importance of these phytochemicals in diets and in medicine. However, the amount of phytochemicals decreased in all the cooked samples.

Conflict of Interest: The authors declare that there is no conflict of interest.

\section{REFERENCES}

Abdul-Rasaq, AA; Abimbola, BW; Kerth, T (2018). The Antinutritional and Vitamin Composition of High-quality Yam Flour. J. of Food Sci.Nutri., 6(8): 1985-1990.

Atoui, AK; Mansouri, A; Boskou, G; Panagiotis, K (2005). Tea and herbal infusions, their antioxidant, activity and phenolic profile. Food Chem. 89:27-36.

Chinedu, N; Ogbuji, OMU (2017). Evaluation of Antinutrients and Mineral Composition of Trifoliate Yam and white cocoyam. J. of Appl. Engr. and Technol., 3(9):

Demigne, C; Sabboh, H; Remesy, C; Meneton, P (2004). Protective effects of high dietary potassium, nutritional and metabolic aspects. $J$. Nutr. 134(11):2903-2906.

Eleazu, CD; Ironic, C (2013), "Physiciochemical Composition and Antioxidant Properties of a Sweet Potato Variety Commercially Cold in South Eastern Nigeria", African J. of Biotech., 12(17): 720-727.

Ezeocha, VC; Ojimelukwe, PC (2012). The Impact of Cooking on the Proximate Composition and Antinutritional Factors of Water Yam. J. of Stored Prod.,3(13): 172-176.

Food and agriculture organization (FAO). (1990). Roots, tubers, plantain, and bananas in human, nutrition, food and agriculture organization of the United Nations, Rome, Italy. 9(6): 23-25.

Joanna, K (2019). Alkaloids: Their importance in nature and for human life. 2019. DOI: 10.5772/Intechopen. 85400
Lewu, MN; Adebola, PO; Afolayan, AJ (2010). Comparative Assessment of the Nutritional Value of Commercially available cocoyam and potato tubers in South Africa. J. of Food Qual., 33: 17454551 .

Navia, J. (2002). Could Tannins explain classic migraine Trigger? (Online), http://www/widomaker.com/jnavia/tannins/tanne $\underline{\mathrm{xpl}}$.htm., as retrieved on Friday.

Okonwu, K; Ugiomoh, IG (2015). Tannin Contents of Some Economics Plants in Nigeria. J. of Plant Sci., 10(4): 159-166.

Reed, JD (1995). Nutritional toxicology of tannins and related polyphenols in forage legumes, J. of Agric. and Food Chem., 28: 824-829.

Salunkhe, DK; Chaven, KS; Kadam, S (1990). Dietary Tannins: Consequences and Remedies. Boca Rafon, FL: CRC press. 4(10): 60-62.

United Nations Development Fund and Women (UNIFEM). (2002). Roots Crops processing, the united Nations Development Fund for women. ITAG publishing, Southampton Row, London WCIB 4HL, UK. 103-105

Vattern, DA; Ghaedian, R; Shetty, K (2005). Enhancing health benefits of barriers through phenolic antioxidant enrichment: Focus on Cranberry. Asia, Pacific J. of Clinic. Nutri., 14(2): 120-130.

Wolke, RL; Parrish, M (2005). What Einstein told his cook 2: The sequel: Further adventures in kitchen science. 2. Norton \& Company. ISBN 978-0-39305-869-7. 384.

Wright, CW; Marshall, SJ; Russel, PF; Anderson, MM; Phillipson, JD; Kirby, GC (2000). In vitro antiplasmodial, antiamoebic and cytotoxic activities of some monomeric isoquinoline alkaloids. J. Nat. Prod., 63:1638-1640 